\title{
Grupos de WhatsApp de padres y sus efectos en la participación educativa: validación de un instrumento
}

\section{Parents' WhatsApp groups and their effects on parental involvement in schools: validation of an instrument}

Paula Coca.

Instituto de Ciencias Empresariales. pcoca@imfice.es

Elvira Carpintero. Universidad Complutense de Madrid. ecarpintero@edu.ucm.es

Eva Expósito-Casas. Universidad Nacional de Educación a Distancia. evaexpositocasas@edu.uned.es

Esther López-Martín. Universidad Nacional de Educación a Distancia, España. estherlopez@edu.uned.es

Bianca Thoilliez. Universidad Autónoma de Madrid bianca.thoilliez@uam.es

\section{RESUMEN.}

La participación educativa de las familias es uno de los principales factores que inciden en la mejora del rendimiento académico. Con las nuevas tecnologías, la importancia creciente que el uso de herramientas de comunicación interactiva como WhatsApp está teniendo en la participación de las familias en la educación escolar exige la realización de estudios dirigidos a analizar empíricamente la misma, pues la participación tradicional está siendo desplazada por nuevas formas de interacción con importantes implicaciones en la dinámica escolar. El estudio muestra los resultados de la validación de un cuestionario dirigido a familias cuyo objetivo es recabar información acerca de dos dimensiones centrales relativas al uso y satisfacción con el WhatsApp en el entorno escolar. El instrumento definitivo, compuesto por 24 ítems, fue aplicado a una muestra de 200 padres y madres y, posteriormente, se llevó a cabo la validación mediante Análisis Factorial Exploratorio (AFE). Los resultados muestran valores elevados de fiabilidad, así como un ajuste de las dimensiones planteadas, validando el cuestionario para su aplicación definitiva.

\section{PALABRAS CLAVE.}

Sistema educativo, familias, participación familiar, Tecnologías de la Información y la Comunicación, grupos de WhatsApp.

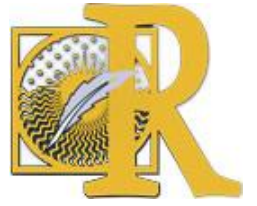

Fecha de recepción: 22-06-2019 Fecha de aceptación: 11-06-2020 


\section{ABSTRACT.}

The educational involvement of families is one of the main factors that affect the improvement of academic performance. With the modern technologies, the increasing importance that the use of interactive communication tools such as WhatsApp is having in the participation of families in school education, requires the realization of studies aimed at empirically analyzing it, since traditional participation is being displaced by new forms of interaction with important implications in school dynamics. The study shows the results of the validation of a questionnaire aimed at families whose objective is to gather information about two central dimensions related to their use and satisfaction. The final instrument, composed of 24 items, was applied to a sample of 200 fathers and mothers and, subsequently, the construct validation was carried out from an Exploratory Factor Analysis (EFA). The results show high reliability values, as well as an adjustment of the proposed dimensions, validating the questionnaire for its final application.

\section{KEY WORDS.}

Educational system, families, parental involvement, Information and Communications Technology, WhatsApp groups.

\section{Introducción.}

La participación, "tomar parte en, formar o ser parte de, y activamente" (Mata, 2006, p. 7) es un concepto ampliamente estudiado en relación con los diferentes ámbitos en los que puede tener lugar: social, comunitaria, política, o educativa (siendo esta última por la que nos preocuparemos en este trabajo).

En la sociedad premoderna, la familia era la principal encargada de la educación de sus descendientes, pero desde la aparición de la educación reglada y su obligatoriedad, pierden esta responsabilidad, pasando a compartirlas con las escuelas. Las familias no quedan excluidas de la vida escolar de sus hijos, sino que pasan a participar en el sistema educativo, lo cual justifica la importancia de establecer regulaciones legales sobre dicha participación (Gaviria, 2014).

Según Epstein (2002), no se pueden entender los procesos educativos en el sistema escolares contemporáneos sin tener en cuenta a las familias, sino que debe existir un trabajo conjunto para poder ofrecer mejores oportunidades. Los vínculos y conexiones que se crean entre escuela, familia y comunidad educativa pueden mejorar el rendimiento y favorecer el trabajo del profesorado. Un sistema educativo que favorezca estas uniones elimina las barreras entre sus miembros, fomentando de manera transversal el crecimiento de los niños en comunidad y la transmisión de valores como la solidaridad, el acompañamiento y la ayuda. Sin embargo, solo el hecho de favorecer estas conexiones no es suficiente, sino que debe apostarse por implicar a las familias y aumentar su poder dentro del centro, para crear relaciones familia-escuela más igualitarias (Bolívar, 2006).

La participación educativa es un concepto complejo, polisémico y multidimensional, que en la práctica oscila entre la mera transmisión de información hasta la consideración en la toma de decisiones dentro del centro (Feito, 2011; Larivée \& Larose, 2014) pudiendo llevarse a cabo de manera individual a través de tutorías, o colectiva por medio de las asociaciones de

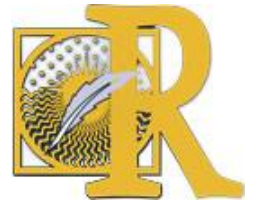


padres o el Consejo Escolar; en niveles más formales con actividades prefijadas por el centro, o informalmente mediante reuniones improvisadas con el profesorado o con otras familias y en espacios diversos como el centro o el hogar. Esto favorece que sea un proceso abierto, dinámico y cambiante, que permite ajustarse a la disponibilidad y circunstancias de las familias (Henderson \& Mapp, 2002; Deslandes \& Bertrand, 2004; Collet \& Tort, 2008; Navaridas \& Raya, 2012; Llevot \& Bernard, 2015). De acuerdo con la ya clásica tipología establecida por Trilla y Novella (2001 y 2010), existen cuatro formas básicas de participación en contextos educativos: (i) participación simple, que es en la que se toma "parte en un proceso o actividad como espectador o ejecutante, sin que el sujeto haya intervenido para nada ni en su preparación ni en las decisiones sobre su contenido o desarrollo" (2001, p. 145); (ii) participación consultiva, que es la que se da allí donde a los sujetos "se les demanda su parecer sobre asuntos que de forma directa o indirecta les conciernen. Se les alienta a opinar, proponer o valorar y se facilitan canales para ello" (lbíd., p. 146-147); (iii) participación proyectiva, que es aquella en la que los sujetos son considerados como agentes de ser preguntados por "¿qué opinas sobre?, ¿qué os ha parecido?", a serlo por "¿qué vamos a hacer?, ¿cómo lo vamos a hacer?" (Ibíd., p. 148); y (iv) metaparticipación, que es aquella que se da cuando los sujetos "piden, exigen o generan nuevos espacios y mecanismos de participación. Aparece cuando un individuo o un colectivo consideran que el reconocimiento de sus derechos participativos no es el debido, o cuando creen que los canales establecidos para ella no son suficientes o eficaces" (Ibíd., p. 150). En este trabajo partimos de la hipótesis que la proliferación y el uso de los grupos de WhatsApp de padres se integra dentro del cuarto tipo de metaparticipación, como una forma emergente de participación familiar en la vida de los centros educativos.

Es importante tener en cuenta la participación familiar, ya que el rendimiento escolar parece explicarse en mayor medida por factores familiares más que educativos (Castro et al., 2014 y 2015; Egido, 2015). Estudios como PISA ofrecen resultados sobre los beneficios de esta participación en el proceso educativo y corroboran la mejora del rendimiento del alumnado cuando en la familia se habla del progreso académico o se les muestra apoyo (OECD, 2013; $2016 ; 2017)$. Este es uno de los indicadores de escuelas de calidad, siendo exitosas aquellas que permiten y fomentan la participación de los padres en los diferentes aspectos escolares (Comeau \& Claes, 1996). La participación familiar en las escuelas ha demostrado, además, tener efectos positivos sobre otros elementos determinantes de la experiencia escolar del alumnado como la prevención de riesgos de bullying y ciberbullying (Kolbert, Schultz, \& Crothers, 2014; Lester et al., 2017), la propia relación educativa entre docentes y alumnos (Vila, 2019; Wright, Shields, Black, \& Waxman, 2018), así como el compromiso de los alumnos con sus trayectorias escolares y su grado de identificación con el centro educativo (Quin, 2016; Roorda et al., 2017). Una situación que entendemos como un fenómeno asociado a las nuevas dinámicas, algunas positivas y otras no tanto, que trae consigo la cultura de la paternidad contemporánea (Fontana, Gil, \& Reyero, 2013; Hodgson \& Ramaekers, 2019).

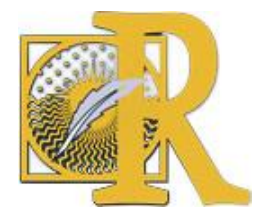

Fecha de recepción: 22-06-2019 Fecha de aceptación: 11-06-2020

Coca, P., Carpintero, E., Expósito-Casas, E., López-Martín, E. \& Thoilliez, B. (2020). Grupos de WhatsApp de padres y sus efectos en la participación educativa: validación de un instrumento International Journal of Educational Research and Innovation (IJERI), 14, 241-261 ISSN: 2386-4303 DOI https://doi.org/10.46661/ijeri.4178 


\subsection{Regulación de la participación de las familias en el sistema educativo español.}

Esta participación comienza a legislarse con la Ley General de Educación de 1970, en la que se enuncia su importancia al tener en cuenta a los padres como uno de los agentes del sistema educativo. Con la llegada de la LOECE (1980) se establece el derecho de las familias a elegir la educación y el centro que consideren más apropiado, y se enuncian los principios de participación educativa por medio de la intervención y gestión de las familias de manera sistemática, con la creación de asociaciones de padres que entran a formar parte de los órganos colegiados del centro y cuentan con un poder real de acción y toma de decisiones. La Ley Orgánica del Derecho a la Educación en 1985, establece nuevas disposiciones como el derecho a la información de las familias sobre el proceso educativo, la participación en la gestión y organización del centro, los deberes relativos a ofrecer los recursos disponibles y necesarios para el desarrollo académico, a la participación y colaboración con los procesos educativos, etc. Asimismo, se establecen los Consejos Escolares como órganos colegiados de gobierno y se definen las funciones de las asociaciones de padres.

La Ley Orgánica de Ordenación general del Sistema Educativo de 1990, añade que la participación de los padres es una de las más importantes para el logro de los objetivos educativos, y por tanto el desarrollo de la docencia se verá estrechamente relacionado con la cooperación de los padres y tutores. En 1995 se promulga la Ley Orgánica de la Participación, la Evaluación y el Gobierno de los centros docentes, que busca "adecuar a la nueva realidad educativa el planteamiento participativo y los aspectos referentes a organización y funcionamiento que se establecieron en la Ley $8 / 1985$, de 3 de julio, Reguladora del Derecho a la Educación" (LOPEG, 1995, p. 33651), y posteriormente, tras la derogada Ley Orgánica de Calidad de la Educación de 2002, la Ley Orgánica de Educación explicita que se debe ofrecer y fomentar la información y la formación en los procesos participativos, o ser incluidos en el conocimiento de los resultados de las evaluaciones internas y externas del centro.

Por último, la Ley Orgánica para la Mejora de la Calidad Educativa de 2013, indica que recae sobre las familias la responsabilidad primera de la educación de los hijos, aunque se resta poder de actuación a los Consejos Escolares.

Adicionalmente a los Consejos Escolares, se encuentran las Asociaciones de Padres y Madres de Alumnos (AMPAS), que se postulan como otro de los caminos para la participación formal en los centros, introduciendo a las familias en la vida escolar. Con la LODE se regulan sus funciones, como dar asistencia a las familias en los aspectos educativos de los hijos, la cooperación en las actividades escolares, promover la gestión y facilitar el acceso a los órganos colegiados (Real Decreto 1533/1986). Si bien la legislación apoya estas funciones, en muchos casos las asociaciones se han convertido en meras gestoras de recursos y servicios (extraescolares y comedor), pasando a ser meras intermediarias, e incluso dejan de contar con el apoyo de los órganos de gobierno, lo que limita sus actuaciones (Garreta, 2008).

\subsection{Nuevas formas de participación.}

Las tecnologías de información y comunicación y su uso cada vez más extendido propician la aparición de nuevas formas de aprendizaje y participación escolar. Como ejemplo, encontramos las plataformas de gestión que pueden sustituir a las tradicionales circulares o

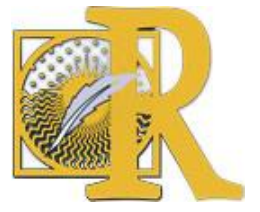

Fecha de recepción: 22-06-2019 Fecha de aceptación: 11-06-2020

Coca, P., Carpintero, E., Expósito-Casas, E., López-Martín, E. \& Thoilliez, B. (2020). Grupos de WhatsApp de padres y sus efectos en la participación educativa: validación de un instrumento International Journal of Educational Research and Innovation (IJERI), 14, 241-261 ISSN: 2386-4303 DOI https://doi.org/10.46661/ijeri.4178 
notas en las agendas, pudiendo acceder a la información del centro en cualquier espacio (desde casa, el trabajo, el transporte...) lo que facilita a los padres el estar informados de lo que ocurre en el ámbito escolar de sus hijos casi a tiempo real y que favorece la conciliación familiar (Hernández \& López, 2006). Estas permiten realizar envíos a modo de circular, ofrecen una agenda donde anotar las tareas y gestionar calendarios, se publican avisos relacionados con aspectos administrativos o con la vida académica del centro, e incluso permiten realizar comunicaciones a través de videoconferencias (Educación 3.0, 2017). De este modo, la participación y el aprendizaje ya no sólo ocurre a las puertas de los centros o dentro de los mismos, sino que se pasa a un modelo de participación y aprendizaje ubicuos por medio de diferentes aplicativos o espacios on-line que favorecen su desarrollo "en cualquier parte y en cualquier momento" (Specht, Tabuenca, \& Ternier, 2013, p. 30), a través de una comunicación informal que crea vínculos con otros padres, se comparte información o se planifican actividades.

Sin embargo, estas plataformas de gestión cuentan aún con un uso minoritario. Por esta razón, por su facilidad, uso habitual y manejo fácil, la aplicación WhatsApp se posiciona como uno de los referentes de las comunicaciones instantáneas para los padres.

\subsubsection{El uso de WhatsApp en la dinámica escolar.}

Creada en el año 2009 por Jan Koum y Brian Acton, WhatsApp nace como una alternativa a los SMS y permite la comunicación instantánea de millones de personas, la creación de grupos, el envío de archivos, etc. a través de una conexión a Internet (WhatsApp Inc, 2017). Como se observa en el Gráfico 1, España es el país de la Unión Europea que en mayor porcentaje emplea las herramientas de comunicación instantánea ( $75 \%$ de habitantes que lo usan habitual y regularmente, frente al $54 \%$ de Francia o al $49 \%$ de Portugal).

Gráfico 1. Frecuencia de empleo de mensajería instantánea \%

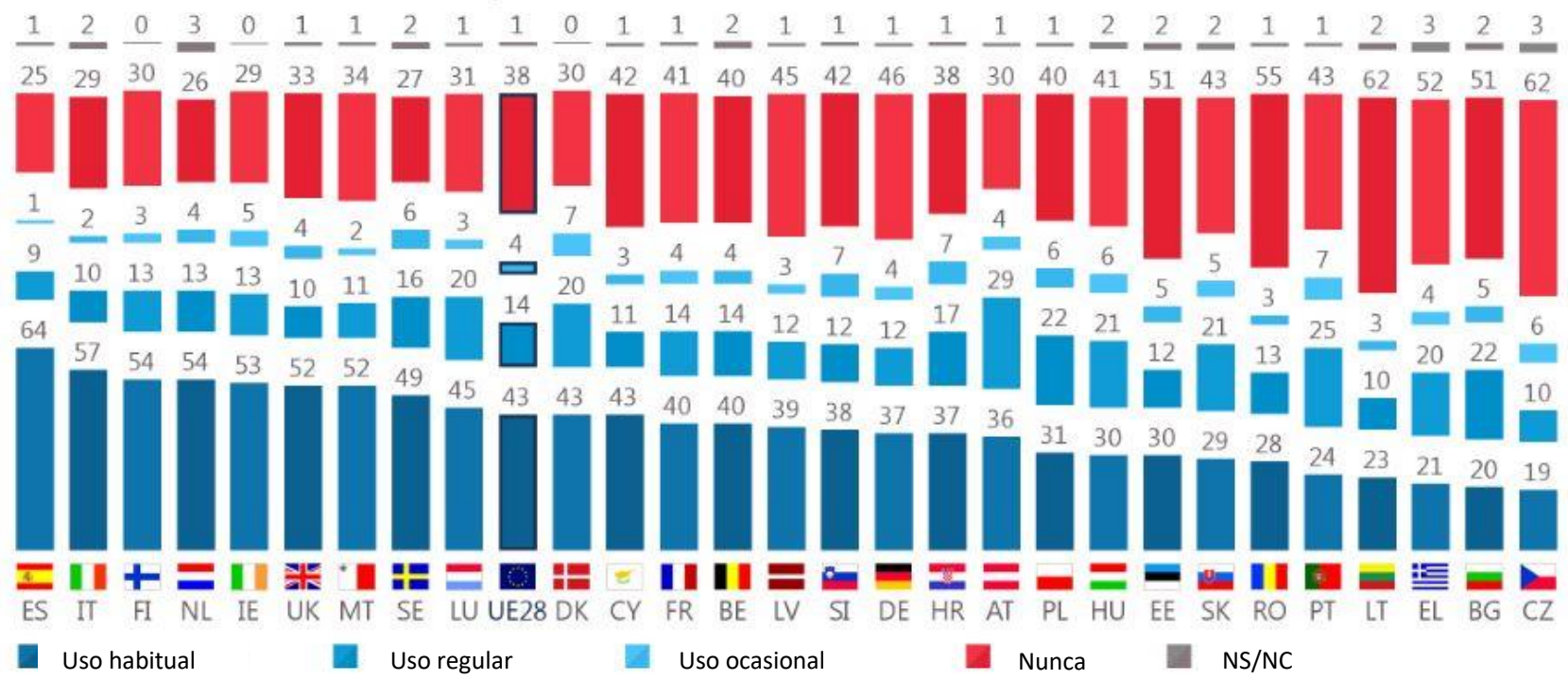

Fuente: (Unión Europea, 2018, p. 13).

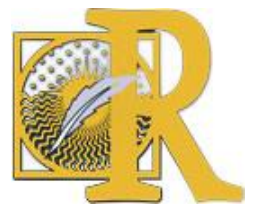


Los datos recogidos en el último barómetro del CIS, muestran que el $89,8 \%$ de los encuestados indicaron que consultaban sus mensajes de WhatsApp u otra aplicación de mensajería instantánea continuamente o varias veces al día, así como que mantienen una media de 11 conversaciones distintas, y queda patente de la misma manera que WhatsApp es la aplicación más empleada con un 98,2\% (Centro de Investigaciones Sociológicas, 2016). WhatsApp se posiciona como la red social más empleada en España, con un perfil de usuario de 38,1 años de media, siendo el 69\% de usuarios mayores de 31 años (IAB, 2018). El éxito de este tipo de herramientas puede deberse a su bajo coste frente al SMS, la creación de grupos y el intercambio de información rápido y en tiempo real (Padrón, 2013).

Estudios demuestran que este tipo de herramientas pueden favorecer la comunicación entre familia y docentes, y, por tanto, la participación en el sistema educativo (Urías et al., 2017), puesto que se pueden generar conexiones que faciliten el flujo de información entre los diferentes miembros de la relación educativa (Gutiérrez, 2012), reforzando así las redes existentes para fortalecer los espacios de aprendizaje (Katileva, 2017). Sin embargo, en algunos casos los docentes se pueden mostrar reticentes a emplearlas por la pérdida de intimidad que puede suponer estar conectado de manera síncrona con las familias (Ruiz et al., 2016).

En lo referente a la participación familiar a través de los grupos de WhatsApp de padres, se trata todavía de un tema poco estudiado, pero parece que son escasas las ocasiones en las que los docentes forman parte de estos, ya que son generalmente grupos exclusivos para padres. Con respecto a su funcionamiento no parecen existir normas específicas, y son considerados útiles pues se percibe que ofrecen información no siempre aportada por el centro (Díez \& Aguilar, 2016). En España, el uso de los grupos de WhatsApp de los padres es un tema recurrente, por lo que diferentes medios de comunicación ofrecen decálogos o consejos para el uso de esta tecnología (Fominaya, 2017; Sánchez, 2016; Santos, 2016). Pero sin duda, los grupos de WhatsApp son una forma de comunicación que puede fomentar y favorecer la participación de los padres en la vida educativa de sus hijos. Esto es debido a que en muchos casos las jornadas laborales son incompatibles con los horarios de la escuela, y la presencia de las familias es necesaria para esta participación (Hernández \& López, 2006; Van Peteghem, 2006). En ocasiones, los centros son impulsores involuntarios de estos grupos de WhatsApp al no trabajar de forma adecuada la difusión de información hacia los padres (Navaridas \& Raya, 2012), o permaneciendo en relaciones no igualitarias hacia la educación de los hijos, al pensar que las familias no van a ser capaces de realizar correctamente las tareas pedagógicas que se les asignen o al no darles la capacidad de toma de decisiones o de intervención en el centro (Parreira do Amaral \& Dale, 2013; Silveira, 2016). Por estas razones, tener un grupo de WhatsApp puede representar la posibilidad de superar estas barreras y crear nuevos espacios de comunicación, donde poder autogestionar y tener el control de la información relativa a sus hijos, escapando así de la relación jerárquica de los modelos tradicionales de participación escolar.

El objetivo de este estudio es ofrecer un instrumento válido de recogida de información para estudiar el empleo y las dinámicas existentes en los grupos de WhatsApp de padres como una nueva forma de participación de las familias en el sistema educativo, dinámicas referidas tanto a su uso como a la satisfacción con el mismo.

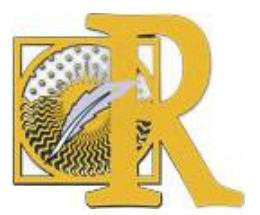

Fecha de recepción: 22-06-2019 Fecha de aceptación: 11-06-2020

Coca, P., Carpintero, E., Expósito-Casas, E., López-Martín, E. \& Thoilliez, B. (2020). Grupos de WhatsApp de padres y sus efectos en la participación educativa: validación de un instrumento International Journal of Educational Research and Innovation (IJERI), 14, 241-261 ISSN: 2386-4303 DOI https://doi.org/10.46661/ijeri.4178 


\section{Material y métodos.}

Se considera efectivo y de fácil aplicación el uso del cuestionario como herramienta de recogida de información. Dicho cuestionario parte de un estudio previo en el que se elabora un instrumento con preguntas abiertas y cerradas estructuradas en tres bloques: variables sociodemográficas de los padres y madres, cuestiones relativas al uso del WhatsApp y valoración de los grupos (Expósito-Casas, López-Martín, \& Thoilliez, 2017). Esta versión original y el análisis de los resultados obtenidos en esta primera aplicación permitió la elaboración del instrumento actual (Anexo 1) compuesto por 24 reactivos estructurados en tres apartados relacionados con el uso de los grupos de WhatsApp como forma de interacción entre padres y satisfacción con los mismos, además de la recogida de información sobre variables sociodemográficas. Los 12 ítems de la dimensión de uso requieren una respuesta cerrada atendiendo a una escala tipo Likert de 5 puntos ( $0=$ Nunca / $1=$ Casi nunca / $2=P o c o$ / $3=$ =Algo / 4=Con mucha frecuencia), del mismo modo, los 12 reactivos de la dimensión de satisfacción utilizan una escala tipo Likert de 5 puntos ( $0=N a d a$ de acuerdo/ $1=$ Poco de acuerdo/2=Algo de acuerdo/3=Bastante de acuerdo/4=Completamente de acuerdo).

\subsection{Población y muestra.}

La población objeto de estudio la constituyen aquellos padres y madres con hijos/as en edad escolar. La unidad de análisis serán los padres y madres que podrían tener acceso a grupos de WhatsApp destinados al contacto entre familias de estudiantes. La muestra obtenida, de carácter incidental, está formada por 200 padres/madres, y cuenta con las siguientes características, tal y como se observa en la Tabla 1:

Tabla 1

Descripción de la muestra

\begin{tabular}{|c|c|c|c|c|}
\hline & & & $\mathrm{n}$ & $\%$ \\
\hline \multirow[t]{8}{*}{ Género y edad } & \multirow[t]{4}{*}{ Hombre } & & 27 & $13,5 \%$ \\
\hline & & $\begin{array}{l}\text { Entre } 20 \text { y } 30 \\
\text { años }\end{array}$ & 0 & $0 \%$ \\
\hline & & $\begin{array}{l}\text { Entre } 30 \text { y } 40 \\
\text { años }\end{array}$ & 7 & $3,5 \%$ \\
\hline & & $\begin{array}{l}\text { Entre } 40 \text { y } 50 \\
\text { años }\end{array}$ & 20 & $10 \%$ \\
\hline & \multirow[t]{4}{*}{ Mujer } & & 173 & $86,5 \%$ \\
\hline & & $\begin{array}{l}\text { Entre } 20 \text { y } 30 \\
\text { años }\end{array}$ & 8 & $4 \%$ \\
\hline & & $\begin{array}{l}\text { Entre } 30 \text { y } 40 \\
\text { años }\end{array}$ & 84 & $42 \%$ \\
\hline & & $\begin{array}{l}\text { Entre } 40 \text { y } 50 \\
\text { años }\end{array}$ & 81 & $40,5 \%$ \\
\hline Total hijos & & & 345 & $100 \%$ \\
\hline \multirow[t]{2}{*}{ Edad hijos } & \multirow[t]{2}{*}{ Hijo 1} & & 200 & $57,97 \%$ \\
\hline & & $\begin{array}{llll}\text { Entre } & 0 & \text { y } & 5 \\
\text { años } & & & \end{array}$ & 52 & $15,07 \%$ \\
\hline
\end{tabular}




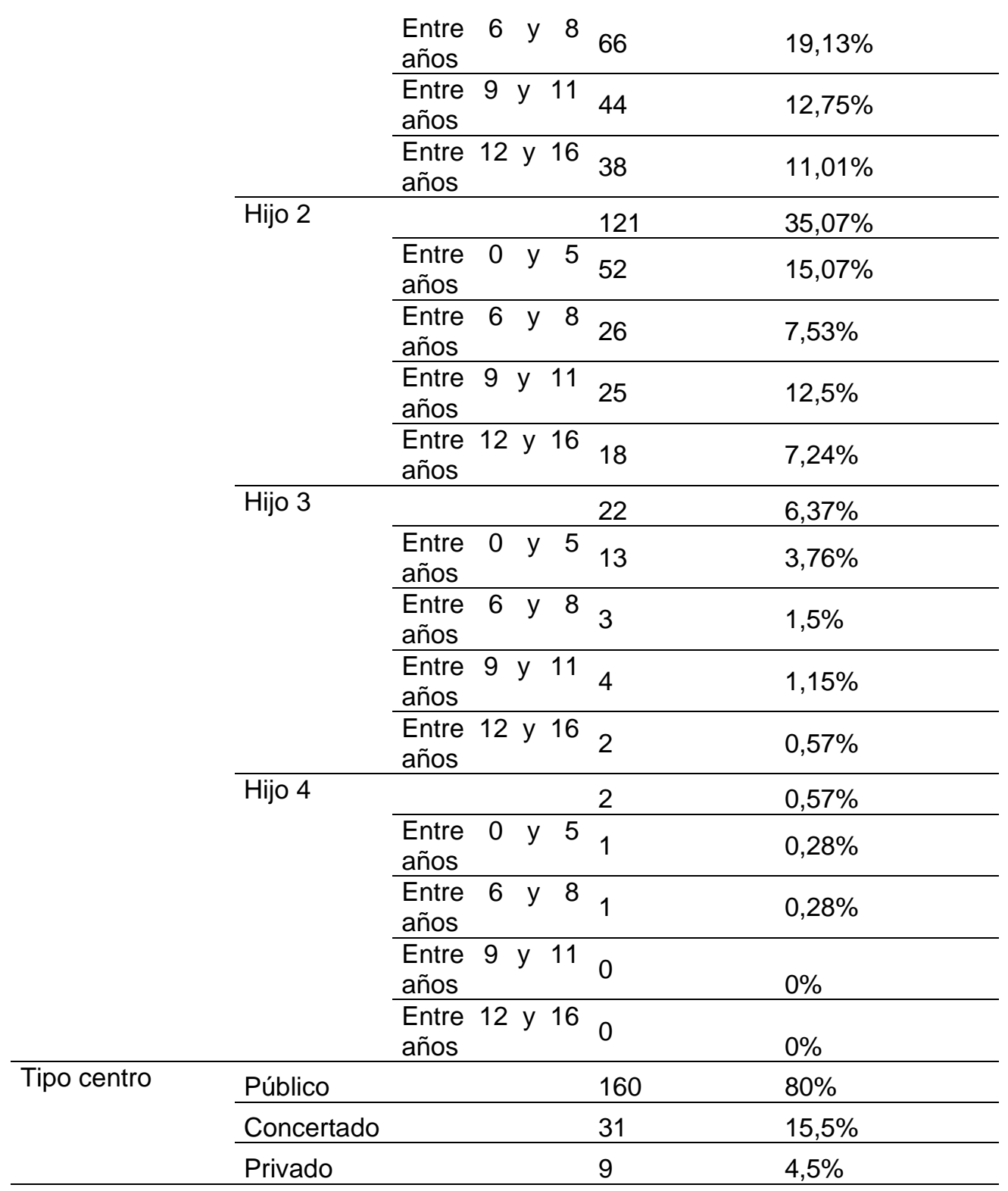

Más del $80 \%$ de la muestra está conformada por mujeres con edades comprendidas entre los 30 y 50 años, y de manera generalizada tienen entre 1 y 2 hijos. Las edades de éstos se sitúan en mayor medida entre 0 y 8 años (los primeros ciclos de educación infantil y primaria) un $62,63 \%$ del total de los niños. A su vez, una amplia mayoría (80\%) de los encuestados tienen escolarizados a sus hijos en centros públicos.

En suma, de estos datos se puede inferir que el perfil medio del encuestado es una mujer de entre 30 y 50 años, que tiene dos hijos en edades comprendidas entre 0 y 8 años y están escolarizados en un centro de titularidad pública.

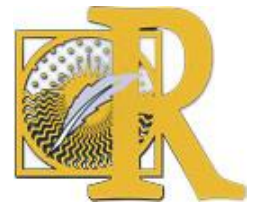




\subsection{Procedimiento.}

La aplicación del instrumento fue llevada a cabo durante el mes de octubre de 2017, período en el que los grupos de WhatsApp vuelven a estar activos con el inicio de curso escolar. Dicha aplicación se realiza sobre un cuestionario alojado en Google Forms y administrado de manera telemática, difundido a través de redes sociales (Facebook) y los propios grupos de WhatsApp de padres, así como a través de varias Federaciones de AMPAS.

\subsection{Análisis de datos.}

Se han analizado las características métricas del instrumento desde un enfoque clásico, estimando la fiabilidad total, así como la relativa a las diferentes dimensiones de la escala, calculando el estadístico Alfa de Cronbach. Posteriormente se ha llevado a cabo un análisis de cada uno de los reactivos y su contribución particular a la escala. A fin de analizar el ajuste a la estructura teórica se ha realizado un análisis factorial exploratorio (AFE). Se empleó el método de Componentes Principales con rotación Oblimin con criterio de normalización de Kaiser para la extracción de los factores, y se retuvieron aquellos factores con autovalor mayor que 1.00. Para asignar los ítems a los factores se consideraron las cargas factoriales iguales o mayores que 0.50 .

El programa de análisis de datos empleado fue IBM-SPSS Statistics 23 (IBM Corp, 2014).

\section{Resultados.}

El coeficiente de fiabilidad obtenido para la escala total ha sido de .902, un valor de fiabilidad excelente atendiendo al criterio de George y Mallery (2003). En el caso de la primera dimensión (uso de los grupos de WhatssApp), el valor de Alfa ha resultado ser de .85 y en la segunda dimensión (satisfacción con los grupos de WhatsApp) .82, lo cual informa de valores de fiabilidad buenos (George \& Mallery, 2003).

Todos los ítems presentan una correlación ítem-test superior a .20, exceptuando el ítem "Evito usarlo para cuestiones sin importancia" que incrementaría la fiabilidad del test de a .908 si se eliminase. Por otro lado, las dos dimensiones propuestas ("uso de los grupos de WhatsApp" y "satisfacción con los grupos de WhatsApp") tienen una correlación alta (por encima de .90) tras emplear la correlación de Pearson, indicando que ambas dimensiones, "uso" y "satisfacción", se encuentran positivamente relacionadas.

Posteriormente se ha realizado un Análisis Factorial Exploratorio (AFE) de Componentes Principales. La prueba KMO y esfericidad de Bartlett indican que realizar un AF de este instrumento es pertinente. Se obtienen 5 componentes, hallándose 5 factores que superan el criterio de Kaiser, con un autovalor igual o superior a 1, y que explican el $64.061 \%$ de la varianza total del test.

En la tabla 3 se muestra la matriz de componentes principales donde pude observarse la distribución de los ítems en los distintos factores hallados.

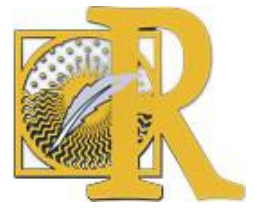

Fecha de recepción: 22-06-2019 Fecha de aceptación: 11-06-2020 
Tabla 3

Matriz de estructura rotada

\begin{tabular}{|c|c|c|c|c|c|}
\hline & \multicolumn{5}{|c|}{ Componente } \\
\hline & 1 & 2 & 3 & 4 & 5 \\
\hline Ítem 1 & ,328 &, 156 &,- 160 &, 223 & ,678 \\
\hline Item 2 &, 473 &, 033 &,- 180 & ,209 & ,766 \\
\hline Ítem 3 & ,337 &, 080 &,- 703 &, 153 &, 531 \\
\hline Item 4 &, 440 &,- 173 &,- 185 & ,363 & ,696 \\
\hline Îtem 5 &, 269 & ,038 &,- 027 & ,755 &, 290 \\
\hline Ítem 6 &, 447 &, 220 &,- 849 & ,324 & 296 \\
\hline Ítem 7 & 324 &, 238 &,- 886 &, 355 &, 302 \\
\hline Item 8 &, 463 &, 300 &,- 871 &, 341 &, 272 \\
\hline Item 9 & ,388 &, 281 &,- 802 & 203 & 342 \\
\hline Item 10 & ,351 &, 232 &,- 505 &, 255 & ,674 \\
\hline Item 11 &, 436 &, 026 &,- 354 & ,753 &, 246 \\
\hline İtem 12 & 234 & ,222 &,- 250 & ,755 &, 165 \\
\hline Item 13 & ,752 &,- 057 &,- 100 &, 362 &, 668 \\
\hline İtem 14 & ,832 &,- 020 &,- 249 & , 486 &, 510 \\
\hline Ítem 15 & ,835 &, 103 &,- 444 &, 248 &, 457 \\
\hline Ítem 16 &, 144 & ,746 &,- 224 &, 081 &, 083 \\
\hline Item 17 &, 118 &, 464 & ,193 &, 172 &, 092 \\
\hline Ítem 18 & ,844 &, 230 &,- 397 & ,245 &, 336 \\
\hline Ítem 19 &, 400 &, 444 &,- 353 &, 246 &, 557 \\
\hline Item 20 & ,696 &, 290 &,- 413 &, 323 &, 396 \\
\hline Item 21 & ,710 &, 157 &,- 391 &, 176 &, 585 \\
\hline İtem 22 & ,750 &, 037 &,- 117 & ,341 & ,295 \\
\hline Item 23 &, 061 & ,733 &,- 198 &, 012 &,- 021 \\
\hline Item 24 &, 044 & ,807 &,- 256 &, 124 &, 141 \\
\hline
\end{tabular}

En relación con el primer factor, puede observarse cómo los reactivos agrupados en torno a este harían referencia a la "utilidad del uso de los grupos de WhatsApp" agrupándose ítems pertenecientes a la segunda dimensión, vinculados con la mejora de la participación en el centro, el conocimiento de la situación de los hijos, el intercambio de información y la mejora de las relaciones.

Analizando los ítems agrupados en el segundo factor, podrían identificarse con "problemas derivados del uso de los grupos de WhatsApp", pues en él saturan los ítems referentes a los problemas que pueden surgir al ser usuario de este tipo de grupos, tales como horarios de utilización inapropiados, exceso de información o el que se generen problemas entre los padres y madres por algún malentendido.

El tercer factor haría referencia al "uso del grupo de WhatsApp en relación con el centro" pues se agrupan ítems relativos a su uso para conocer información relativa al centro, la clase y el profesor, así como la posibilidad que estos ofrecen de solucionar y aclarar problemas relacionados con los niños (malentendidos, comportamiento...).

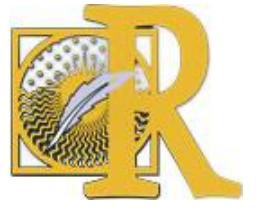

Fecha de recepción: 22-06-2019 Fecha de aceptación: 11-06-2020 
Por su parte, el cuarto factor se vincularía con el "uso externo al centro". Estando conformado por tres ítems concernientes a lo que ocurre fuera del centro que puede ser de interés para las familias, como la organización de actividades o cumpleaños, compartir imágenes o tratar temas de componente no educativo.

Por último, el quinto factor haría referencia a una subdimensión particular del "uso del grupo de WhatsApp como agenda". En este caso, se encuentran cuatro ítems muy relacionados con la realización de consultas (de los deberes y dudas de los hijos/as), los horarios de verano y las actividades del centro.

Tras este análisis factorial, las dos dimensiones inicialmente propuestas, "uso de los grupos de WhatsApp" y "satisfacción con los grupos de WhatsApp" parecen mantenerse y dividirse en subdimensiones más específicas, pues la dimensión de uso podría presentar tres subdimensiones relativas al uso en relación con el centro, como agenda y para cuestiones extraescolares (factores 3,4 y 5). La dimensión de satisfacción podría ser renombrada como "implicaciones" pues en ella se incluirían dos subdimensiones relativas a utilidad y problemas derivados de un uso inadecuado (factores 1 y 2 ).

De esta manera, con las dos dimensiones ya establecidas claramente, "uso del grupo de WhatsApp" e "implicaciones de uso del grupo de WhatsApp", tras eliminar el ítem "evito utilizarlo para cuestiones de poca importancia", que podría pertenecer a la dimensión "problemas derivados del uso de los grupos de WhatsApp", pero con una saturación saturación menor a .500 en la matriz (.464), el cuestionario podría estar listo para su aplicación, configurándose un instrumento final de 23 ítems y 5 subdimensiones, de modo que pueda ser aplicado con facilidad y eficiencia.

\section{Discusión.}

La participación de las familias en la vida escolar de sus hijos es un aspecto fundamental tanto para la mejora del rendimiento académico como indicador de calidad de los centros educativos (Comeau \& Claes, 1996; Borgonovi \& Montt, 2012; OECD, 2016; OECD, 2017), fenómeno legislado y ampliamente estudiado.

La comunicación es uno de los factores que posibilita y permite la participación, pues se trata de conceptos íntimamente relacionados que permite el intercambio de información (Epstein, 2002). Sin embargo, las circunstancias actuales, como una jornada laboral más extensa de los padres, o el control de dicha participación por parte de los centros, hace que se deban buscar nuevas formas y espacios de comunicación y participación.

La herramienta de mensajería instantánea WhatsApp permite superar la dificultad de los horarios y la imposibilidad en muchos casos de asistir de manera presencial al centro y poder establecer comunicaciones con las familias o equipos docentes, reforzando así la formación de conexiones que posibiliten la transmisión de información, en cualquier espacio e instante (Gutiérrez, 2012; Specht, Tabuenca \& Ternier, 2013). Asimismo, se rompe la barrera existente entre las características personales, culturales y socioeconómicas de los padres, que en ocasiones condicionan un mayor o menor acercamiento al centro, y les hace situarse fuera de la relación jerárquica que se crea en la participación formal en los centros (Parreira do Amaral \& Dale, 2013), lo que fomenta un protagonismo en este manejo de la información.

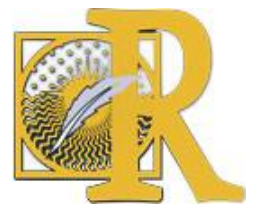

Fecha de recepción: 22-06-2019 Fecha de aceptación: 11-06-2020 
De esta manera los padres pueden alcanzar una percepción de empoderamiento dentro de la educación de sus hijos, pasando a ser agentes activos que pueden tomar decisiones relevantes.

Para que la participación efectiva de los padres en el sistema educativo sea un hecho, los centros deben apostar por implicar a las familias, incrementando su papel y adaptando la implicación a los requerimientos de la vida profesional y familiar (Bolívar, 2006). Disponer de un instrumento válido que permita conocer más a fondo este fenómeno es por tanto necesaria, para poder saber en qué punto los grupos de padres de WhatsApp inciden en el proceso participativo y qué beneficios se obtiene de ello, para quizá establecer pautas de uso o formar tanto a padres como al personal de los centros educativos para hacer de esta herramienta una verdadera aliada para que pueda trabajar al servicio de la mejora de las experiencias educativas de los niños y de la calidad de la vida escolar en los centros educativos. Por estas razones, es incontestable que el conocimiento de este fenómeno no debe quedarse únicamente en este estadio, sino que hay que seguir estudiándolo en profundidad, y por ello se ha trabajado para tener un instrumento de medición fiable y adecuado para la aplicación a una muestra representativa de la población. Es por ello que, aunque la investigación sobre el uso de los grupos de WhatsApp de padres y su implicación en la participación escolar ha sido poco estudiada, se muestra como una interesante oportunidad para apoyar y acompañar la vida escolar de los hijos (Díez \& Aguilar, 2016).

Todas estos argumentos inciden en la necesidad de estudiar este fenómeno de forma sistemática, para poder conocer realmente qué sucede con estos grupos y cómo su uso puede afectar a la participación de las familias en el sistema educativo. No puede obviarse que nace así una posible línea de trabajo para los centros, a la hora de consensuar con los padres el tipo de información que desean recibir y la manera óptima de hacerlo, ya que uno de los puntos fuertes de estos grupos es la transmisión de información, fundamental para la comunicación y, por ende, la participación en los centros educativos. Conocer hoy las formas en que se concretan la participación de las familias en las escuelas, como indicador de su implicación y compromiso en la vida escolar de sus hijos, no puede limitarse ya a la consideración de los canales formales y regulados de participación. El estudio sistemático de novedades de metaparticipación escolar (Trilla y Novella, 2001 y 2011) como los grupos de padres de WhatsApp, se encuentra entre esas nuevas dimensiones que merecerán la atención de profesionales e investigadores interesados en mejorar las relaciones familiaescuela. El instrumento aquí presentado es una herramienta desde la que poder iniciar esta necesaria indagación.

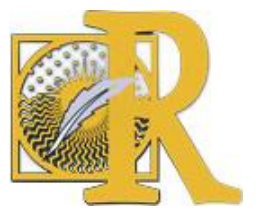

Fecha de recepción: 22-06-2019 Fecha de aceptación: 11-06-2020 


\section{Referencias}

- Bolívar, A. (2006). Familia y escuela: dos mundos llamados a trabajar en común. Revista de Educación, 339, 119-146.

- Borgonovi, F., \& Montt, G. (2012). Parental Involvement in Selected PISA Countries and Economies. Paris: OECD Publishing. Doi:http://dx.doi.org/10.1787/5k990rk0jsjj-en

- Castro, M., Expósito-Casas, E., Lizasoain, L., López-Martín, E., \& Navarro-Asencio, E. (2014). Participación familiar y rendimiento académico. Una síntesis meta-analítica. En, Consejo Escolar del Estado (Ed.), La participación de las familias en la educación escolar (pp. 83-105). Madrid: Ministerio de Educación, Cultura y Deporte.

- Castro, M., Expósito-Casas, E., López-Martín, E., Lizasoain, L., Navarro-Asencio, E., \& Gaviria, J. L. (2015). Parental involvement on student academic achievement: A metaanalysis. Educational Research Review, 14, 33-46. doi: 10.1016/j.edurev.2015.01.002

- Centro de Investigaciones Sociológicas. (2016). Barómetro de febrero 2016, Distribuciones Marginales.

- Collet, J., \& Tort, J. (2008). Espacios de participación. Cuadernos de Pedagogía (378), 5760.

- Coumeau, J., \& Claes, M. (1996). L'école et la famille: deux mondes? Lien social et politiques - RIAC, 35, 75-85.

- Deslandes, R., \& Bertrand, R. (2004). Motivation des parents à participer au suivi scolaire de leur enfant au primaire. Revue de sciences de l'éducation, 30(2), 411-433.

- Díez, R., \& Aguilar, B. (2016). Los grupos de WhatsApp escolares: una oportunidad para mejorar la comunicación familia-escuela. En R. Roig-Vila, Tecnología, innovación e investigación en los procesos de enseñanza-aprendizaje (343-351). Barcelona: OCTAEDRO.

- Educación 3.0. (2017). Plataformas para la gestión de centros educativos. Recuperado de http://www.educaciontrespuntocero.com/novedades2/plataformas-gestionescolar/12663.html

- Egido, I. (2015). Las relaciones entre famila y escuela. Una visión general. Participación Educativa, 4(7), 11-17.

- Epstein, J. (2002). School, Family, and Community Partnerships: Caring for the Children We Share. En J. Epstein, M. Sanders, B. Simon, K. Clark Salinas, N. Rodriguez Jansorn, \& F. Van Voorhis, School, Family, and Community Partnerships (pág. 380). California: Corwin Press, INC.

- Expósito-Casas, E., López-Martín, E., \& Thoilliez, B. (2017). Cuestionario dirigido a las familias sobre el uso de la aplicación WhatsApp en cuestiones escolares. Los grupos de padres/madres [documento de trabajo].

- Feito, R. (2011). Los retos de la participación escolar. Elección, control y gestión de los centros educativos. Madrid: Morata.

- Fominaya, C. (2017). Qué hacer (y qué no) en el grupo de WhatsApp de padres del colegio. $A B C$.

- Fontana, M., Gil, F., \& Reyero, D. (2013). La perspectiva pedagógica de la vida familiar. Un enfoque normativo. Estudios sobre Educación, 25, 115-132.

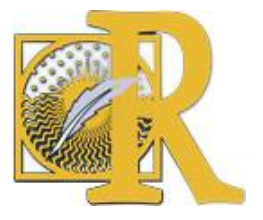


- Garreta, J. (2008). La participación de las familias en la escuela pública: las Asociaciones de Madres y Padres del Alumnado. Madrid: CEAPA.

- Gaviria, J. L. (2014). Prólogo. En, Consejo Escolar del Estado (Ed.) La participación de las familias en la educación escolar (pp. 13-18). Madrid: Ministerio de Educación, Cultura y Deporte.

- George, D., \& Mallery, P. (2003). SPSS for Windows step by step: A Simple Guide and Reference. 11.0 update (4 ed.). Boston: Allyn \& Bacon.

- Gutiérrez, L. (2012). Conectivismo como teoría de aprendizaje: conceptos, ideas, y posibles limitaciones. Revista Educación y Tecnología, (1), 111-122.

- Henderson, T., \& Mapp, K. (2002). A new wave of evidence: The impact of school, family and community connections on student achievement. Austin (Texas): Southwest Educational Development Laboratory.

- Hernández, M., \& López, H. (2006). Análisis del enfoque actual de la cooperación padres y escuela. Aula Abierta, 87, 3-26.

- Hodgson, N., \& Ramaekers, S. (2019). Parenting, Upbringing, and Educational Philosophy. In, Philosophical Presentations of Raising Children. The Grammar of Upbringing (pp. 3-26). London: Palgrave Macmillan. doi: 10. 1007/978-3-030-12540-0_1

- IAB. (2018). Estudio Anual de Redes Sociales 2018. Recuperado de https://iabspain.es/wp-content/uploads/estudio-redes-sociales-2018_vreducida.pdf

- IBM Corp. (2014). IBM-SPSS Statistics for Windows, Version 23.0. Armonk, NY: IBM Corp.

- Katileva, E. N. (2017). La unión entre el Conectivismo y las TIC para el aprendizaje del inglés en secundaria. En REDINE (Ed.). Trabajo presentado en Edunovatic 2017, Conference Proceedings, 2nd Virtual International Conference on Education, Innovation and ICT (831-836). Eindhoven: Adaya Press.

- Kolbert, J. B., Schultz, D., \& Crothers, L. M. (2014). Bullying Prevention and the Parent Involvement Model. Journal of School Counseling, 12(7), 1-20.

- Larivée, S., \& Larose, F. (2014). Les programmes d'implication parentale efficaces en milieux défavorisés: une rencension des écrits. La revue internationale de l'éducation familiale, 36(2), 35-60. Doi:10.3917/rief.036.0035

- Lester, L., Pearce, N., Waters, S., Barnes, A., Beatty, S., \& Cross, D. (2017). Family Involvement in a Whole-School Bullying Intervention: Mothers' and Fathers' Communication and Influence with Children. Journal of Child and Family Studies, 26(10), 2716-2727. doi: 10.1007/s10826-017-0793-6

- Ley 14/1970, de 4 de agosto, General de Educación y Financiamiento de la Reforma Educativa. Boletín Oficial del Estado, núm. 187, de 6 de agosto de 1970, 12525-12546.

- Ley Orgánica 5/1980, de 19 de junio, por la que se regula el Estatuto de Centros Escolares. Boletín Oficial del Estado, núm. 154, de 27 de junio de 1980, 14633-14636.

- Ley Orgánica 8/1985, de 3 de julio, reguladora del Derecho a la Educación. Boletín Oficial del Estado, núm. 159, de 4 de julio de 1985, 21015-21022.

- Ley Orgánica 1/1990, de 3 de octubre, de Ordenación General del Sistema Educativo. Boletín Oficial del Estado, núm. 238, de 4 de octubre de 1990, 28927-28942.

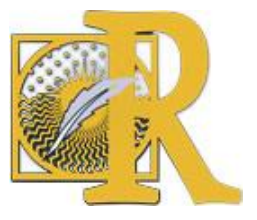

Fecha de recepción: 22-06-2019 Fecha de aceptación: 11-06-2020 
- Ley Orgánica 9/1995, de 20 de noviembre, de la participación, la evaluación y el gobierno de los centros docentes. Boletín Oficial del Estado, núm. 278, de 21 de noviembre de 1995, 33651-33665.

- Ley Orgánica 2/2006, de 3 de mayo, de Educación. Boletín Oficial del Estado, núm. 106, de 4 de mayo de 2006, 17158-17207.

- Ley Orgánica 8/2013, de 9 de diciembre, para la mejora de la calidad educativa. Boletín Oficial del Estado, núm. 295, de 10 de didiembre de 2013, 97858-97921.

- Llevot, N., \& Bernard, O. (2015). La participación de las familias en la escuela: Factores clave. Revista de la Asociación de Sociología de la Educación, 8(1), 57-70.

- Mata, M. (2006). "Participar" una genealogía particular. Participación Educativa(1), 7.

- Navaridas, F., \& Raya, E. (2012). Indicadores de participación de los padres en el sistema educativo: un nuevo enfoque para la calidad educativa. Revista Española de Educación Comparada, 20, 223-248.

- OECD. (2013). PISA 2012 Results: What Makes School Successful? Resources, Policies and Practices (Volume IV). Paris: PISA, OECD Publishing. Doi:10.1787/9789264201156en

- OECD. (2016). PISA 2015 Results (Volume II): Policies and Practices for Successful Schools. Paris: PISA, OECD Publishing. Doi:10.1787/9789264267510-en

- OECD. (2017). PISA 2015 Results (Volume III): Students' Well-Being. Paris: PISA, OECD Publishing. Doi:10.1787/9789264273856-en

- Padrón, C. J. (2013). Estrategias Didácticas basadas en Aplicaciones de Mensajería Instantánea WhatsApp exclusivamente para Móviles (Mobile Learning) y el uso de la Herramienta para promover el Aprendizaje Colaborativo. Revista de Tecnología de Información y Comunicación en Educación, 7(2), 123-134.

- Parreira do Amaral, M., \& Dale, R. (Eds.). (2013). Governance of Educational Trajectories in Europe. Thematic Report on Governance [Goete Working Paper]. Frankfurt: Universidad de Frankfurt.

- Quin, D. (2016). Longitudinal and Contextual Associations Between Teacher-Student Relationships and Student Engagement: A Systematic Review. Review of Educational Research, 87(2), 345-387. doi: 10.3102/0034654316669434

- Real Decreto 1533/1986, de 11 de julio, por el que se regulan las asociaciones de padres de alumnos. Boletín Oficial del Estado, 26858-268509.

- Roorda, D. L., Jak, S., Zee, M., Oort, F. J., \& Koomen, H. M. Y. (2017). Affective TeacherStudent Relationships and Students' Engagement and Achievement: A Meta-Analytic Update and Test of the Mediating Role of Engagement. School Psychology Review, 46(3), 239-261. doi: 10.17105/SPR-2017-0035.V46-3

- Ruiz, D., Seva, P., \& Seva, S. (2016). Relación vía Whatsapp entre padres y maestros/as. Perspectiva de futuro docente. En R. Roig-Vila (Ed.) Tecnología, innovación e investigación en los procesos de enseñanza-aprendizaje (pp. 1233-1240). Barcelona: Octaedro.

- Sánchez, D. (2016). Los grupos de Whatsapp de padres, la última pesadilla para los profesores. Eldiario.es.

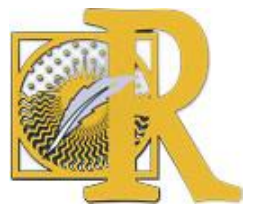

Fecha de recepción: 22-06-2019 Fecha de aceptación: 11-06-2020

Coca, P., Carpintero, E., Expósito-Casas, E., López-Martín, E. \& Thoilliez, B. (2020). Grupos de WhatsApp de padres y sus efectos en la participación educativa: validación de un instrumento International Journal of Educational Research and Innovation (IJERI), 14, 241-261 ISSN: 2386-4303 DOI https://doi.org/10.46661/ijeri.4178 
- Santos, E. (2016). ¿Qué pasa en los grupos de WhatsApp de los padres del colegio? The Huffington Post.

- Silveira, H. (2016). La participación de las familias en los centros educativos. Un derecho en construcción. Revista Electrónica Interuniversitaria de Formación del Profesorado, 19(1), 17-29.

- Specht, M., Tabuenca, B., \& Ternier, S. (2013). Tendencias del aprendizaje ubicuo en el internet de las cosas. Campus Virtuales, 2(2), 30-44.

- Trilla, J., \& Novella, A. (2001). Educación y participación social de la infancia. Revista Iberoamericana de Educación, 26, 137-164.

- Trilla, J, \& Novella, A. (2011). Participación, democracia y formación para la ciudadanía. Los consejos de infancia. Revista de Educación, 356, 23-43.

- Unión Europea. (2018). Eurobaromètre spécial 462 - Les communications électroniques et le marché unique numérique. Comisión Europea.

- Urías, M., Urías, M., \& Valdés, Á. (2017). Creencias docentes del uso de tecnologías por familias para involucrarse en educación. Apertura, 9(2), 148-159. Doi:10.18381/Ap.v9n2.1100

- Van Peteghem, O. (2006). Quelles pistes envisager face à la baisse de la participation parentale? Bruxelles: Fédération des associations de parents de l'enseignement officiel.

- Vila, E. (2019). Repensar la relación educativa desde la pedagogía de la alteridad. Teoría de la Educación. Revista Interuniversitaria, 31(2), 177-196. doi: 10.14201/teri.20271

- WhatsApp Inc. (2017). Acerca de WhatsApp. Recuperado de https://www.whatsapp.com/about/

- Wright, K. B., Shields, S. M., Black, K., \& Waxman, H. C. (2018). The Effects of Teacher Home Visits on Student Behavior, Student Academic Achievement, and Parent Involvement. School Community Journal, 28(1), 67-90. 


\section{Anexos}

\section{Anexo 1}

\section{Cuestionario "Grupos de WhatsApp de padres y madres en la escuela"}

\section{Grupos de WhatsApp de padres y madres en la escuela}

A través de esta encuesta deseamos conocer algunos datos básicos sobre la utilización del servicio de mensajería WhatsApp entre los grupos de padres y madres, a fin de explorar las características de su uso, su incidencia en la relación familia-escuela, su utilidad, así como sus posibles limitaciones.

La participación es voluntaria y sus respuestas anónimas. Agradecemos su colaboración.

Atentamente,

Equipo Investigador

Indíquenos su sexo:

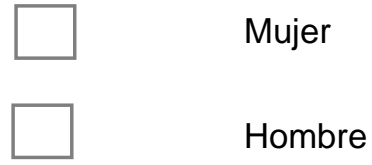

Indíquenos su edad:

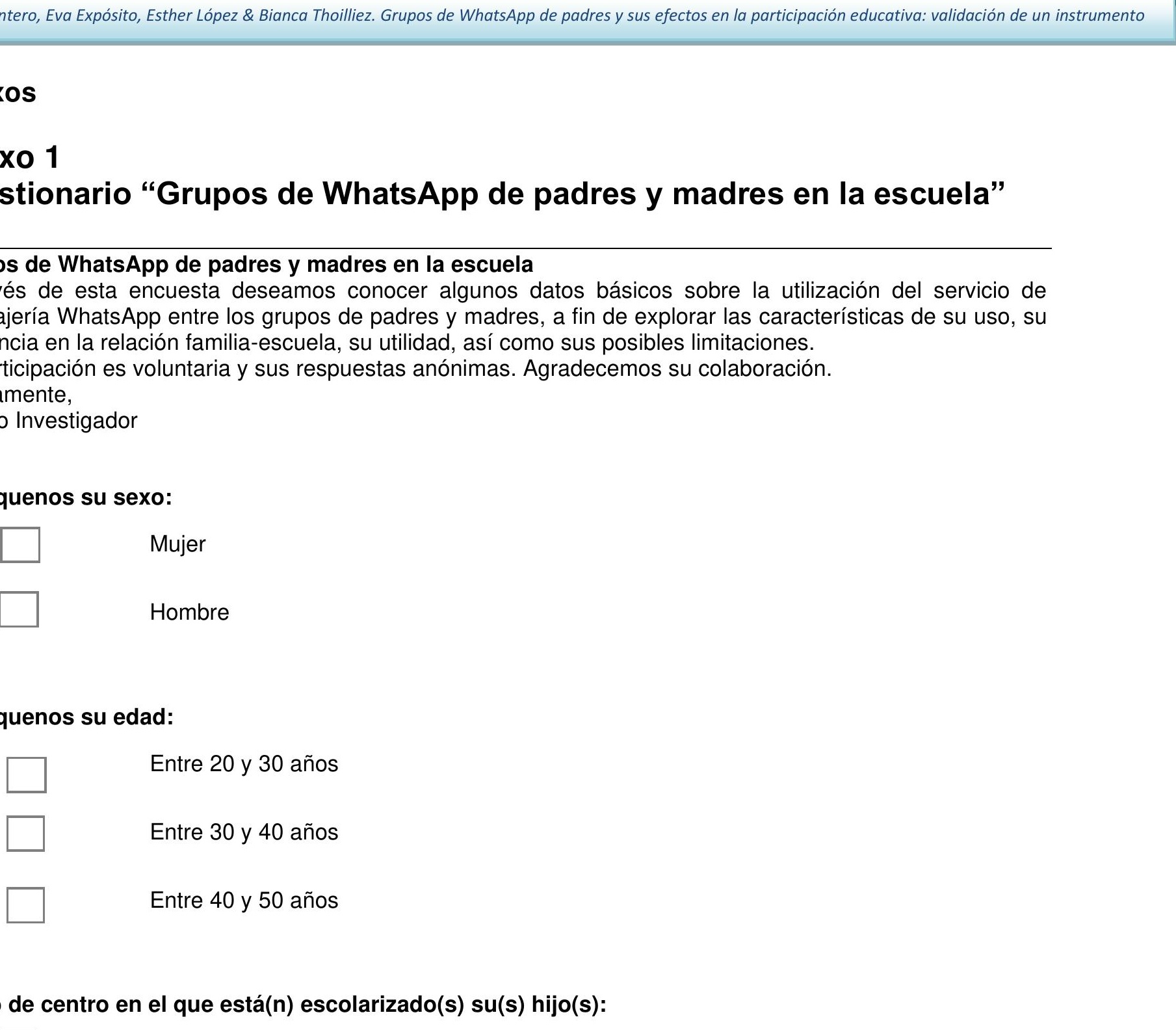

Tipo de centro en el que está(n) escolarizado(s) su(s) hijo(s):

Público

Concertado

Privado

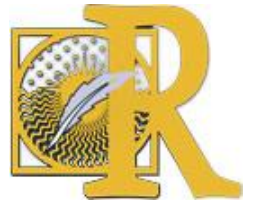


Indique la edad de su(s) hijo(s):

De 0 a 5 años

De 6 a 8 años

De 9 a 11 años

De 12 a 16

años

Hijo 1
Hijo 2
Hijo 3
Hijo 4
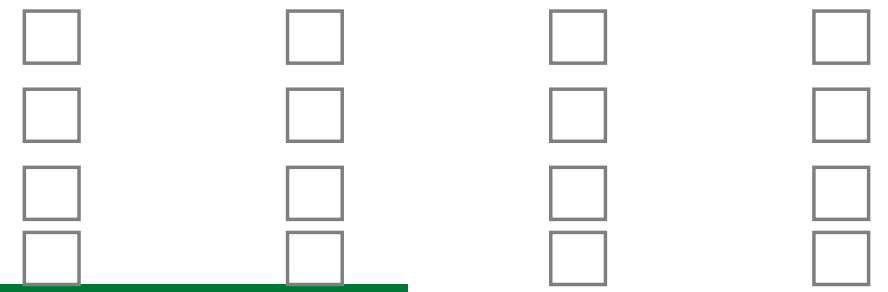

Uso de grupo de WhatsApp

A continuación, se presenta un listado con diferentes usos a los que puede estar destinado este grupo de WhatsApp. Por favor, valore en una escala de 0 (nunca) a 4 (mucha frecuencia) el "uso" real que usted da a este grupo de WhatsApp:

$\begin{array}{cccc}2 & \text { Algunas } & 3 \text { Con } & 4 \text { Con mucha } \\ \text { veces } & \text { frecuencia } & \text { frecuencia }\end{array}$

Para consultar tareas (deberes) de mis hijos/as
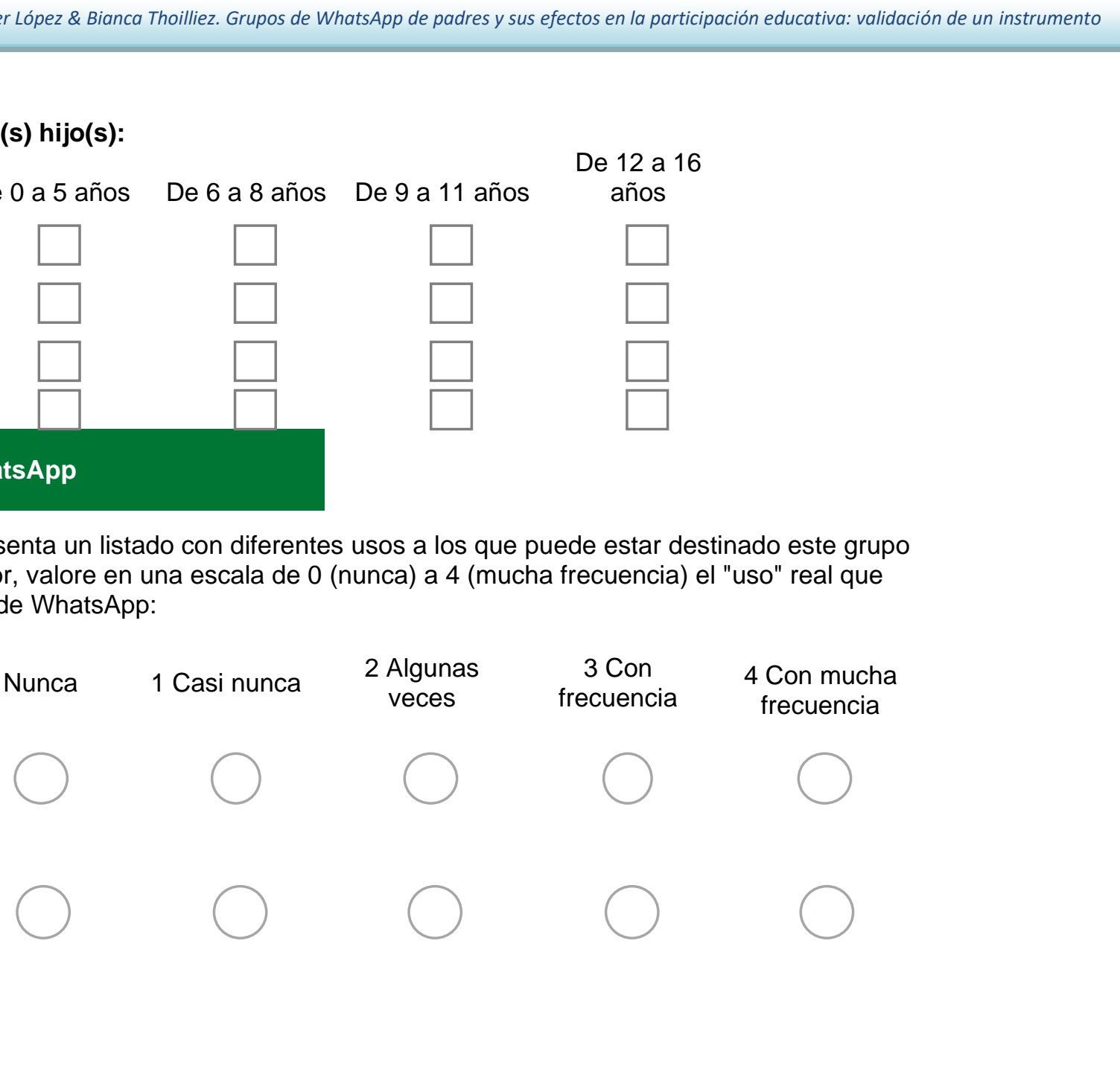

Como agenda escolar, para conocer las actividades del
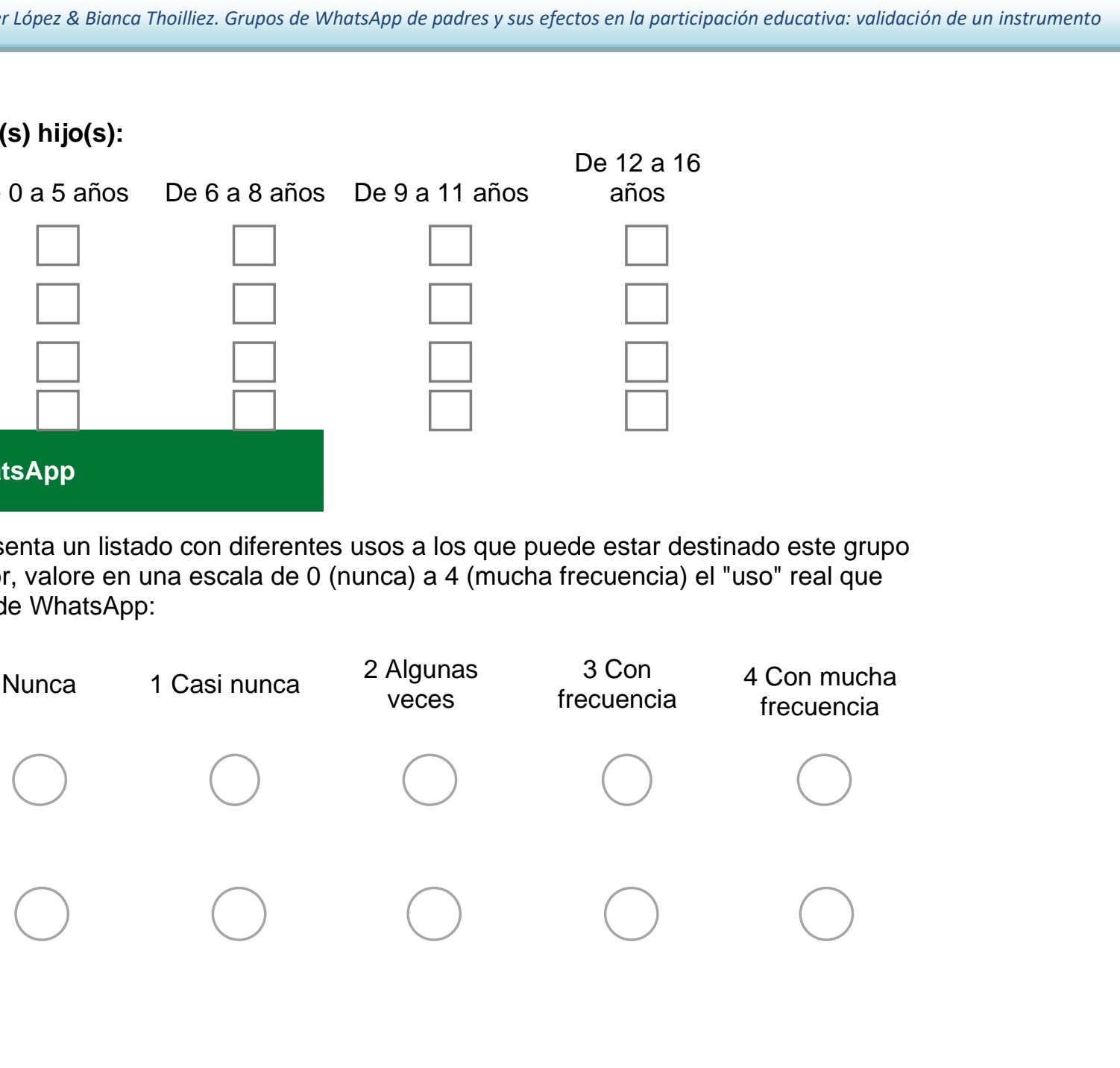
centro

Para tratar problemas relacionados con el comportamiento
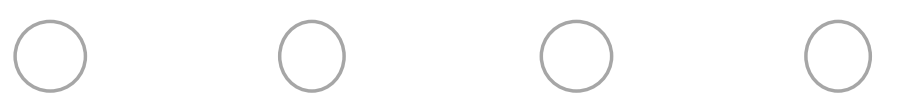
de los niños/as en el centro Consulta de dudas relacionadas con horarios de verano, vacaciones, periodos no lectivos, etc. 
Organización de actividades fuera de la escuela como cumpleaños

Para conocer la opinión de otros padres/madres en relación al funcionamiento del centro

Para conocer la opinión de otros padres/madres en relación al funcionamiento de la clase

Para conocer la opinión de otros padres/madres en relación al trabajo docente

\section{Aclarar} malentendidos surgidos entre los niños/as

Consultar dudas por demanda de nuestros hijos/as

Compartir imágenes, recursos de audio o vídeos de los niños/as

\section{Tratar temas} ajenos al centro
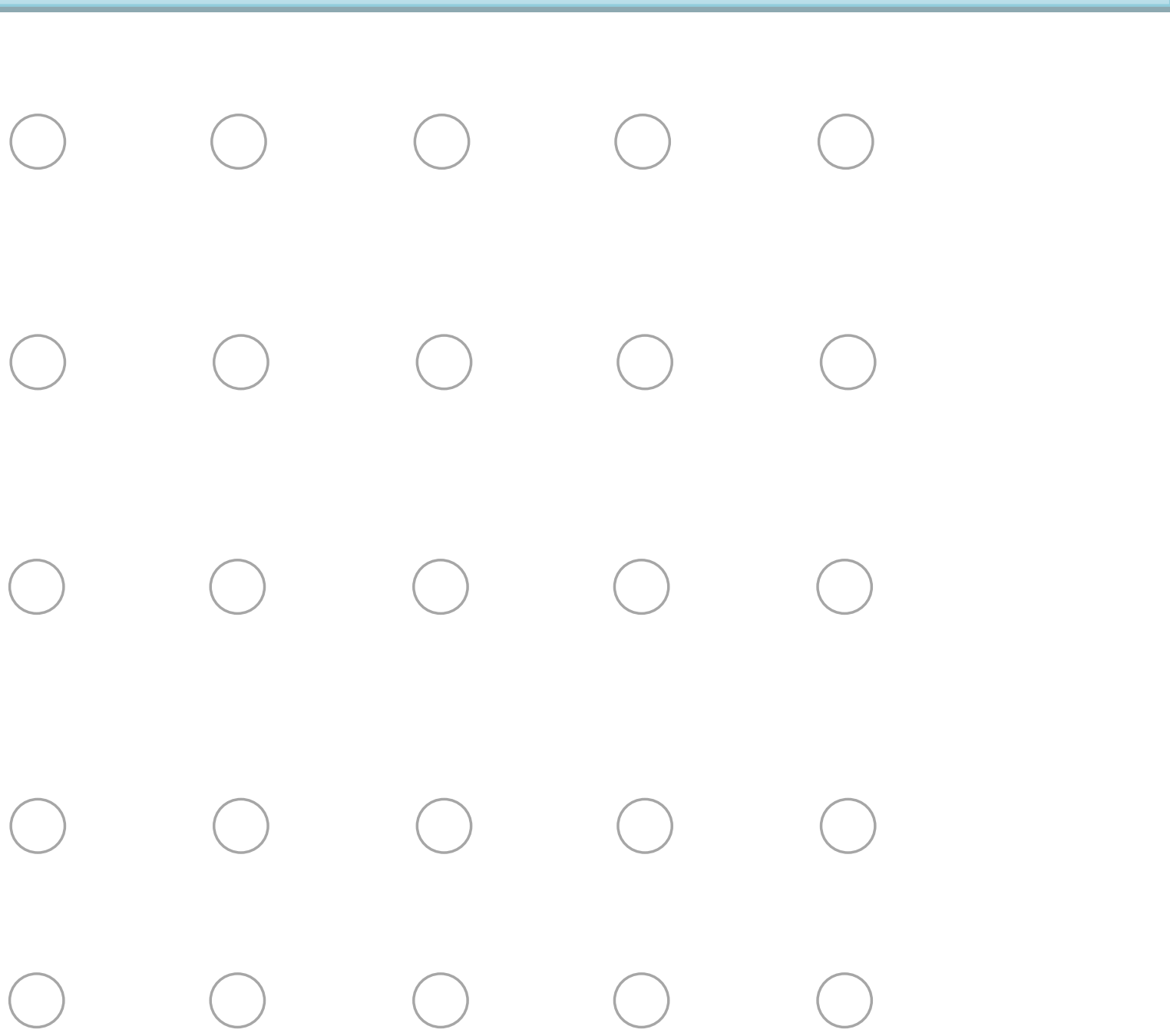

Otros, por favor, especifique cual/cuales

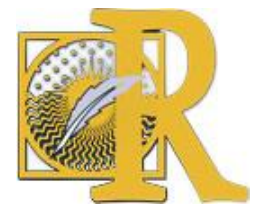

Fecha de recepción: 22-06-2019 Fecha de aceptación: 11-06-2020

Coca, P., Carpintero, E., Expósito-Casas, E., López-Martín, E. \& Thoilliez, B. (2020). Grupos de WhatsApp de padres y sus efectos en la participación educativa: validación de un instrumento International Journal of Educational Research and Innovation (IJERI), 14, 241-261 


\section{Satisfacción con el grupo de WhatsApp}

Por último, nos gustaría conocer su grado de satisfacción con el uso del WhatsApp por parte de los padres y madres. Por favor, responda a las siguientes afirmaciones marcando su grado de acuerdo con las mismas, siendo 0 "Nada de acuerdo" y 4 "Completamente de acuerdo":

$\begin{array}{ccccc}0 \text { Nada de } & 1 \text { Poco de } & 2 \text { Algo de } & 3 \text { Bastante de } & 4 \\ \text { acuerdo } & \text { acuerdo } & \text { acuerdo } & \text { acuerdo } & \begin{array}{c}\text { Completamente } \\ \text { de acuerdo }\end{array}\end{array}$

El grupo de WhatsApp me ayuda a estar mejor<smiles>c1ccccc1</smiles><smiles>c1ccccc1</smiles><smiles>c1ccccc1</smiles><smiles>c1ccccc1</smiles>

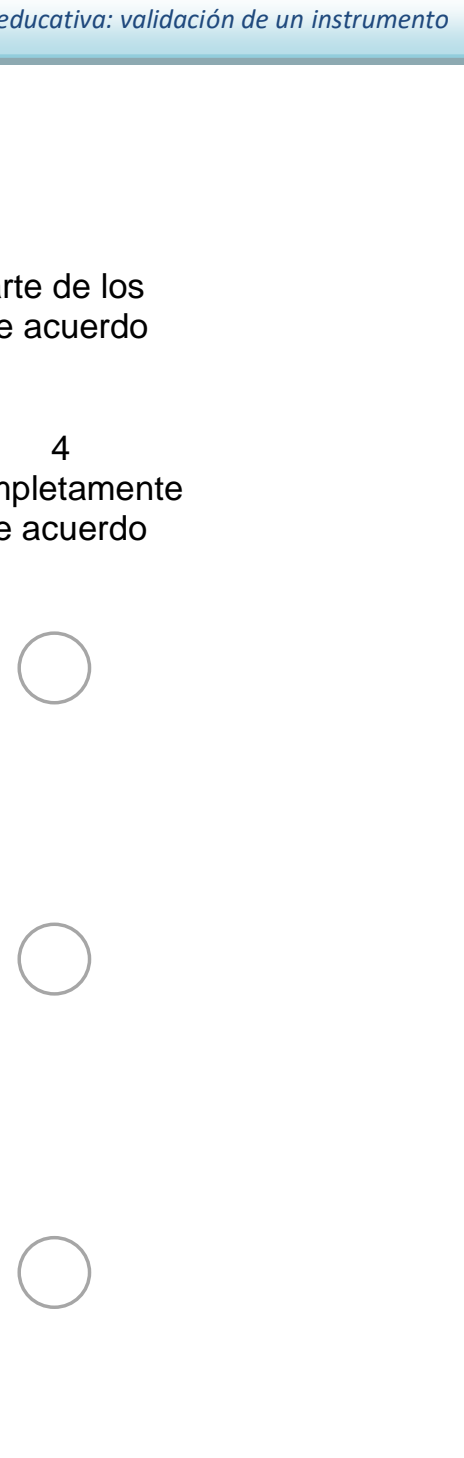
informado/a

Gracias a su uso tengo mejor relación con los padres/madres $y$ compañeros/as de mis hijos/as

Su uso me ha permitido conocer mejor la situación de mis hijos/as en el centro

En ocasiones me siento abrumado/a por el volumen de información

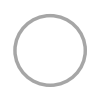<smiles>c1ccccc1</smiles><smiles>c1ccccc1</smiles><smiles>c1ccccc1</smiles>

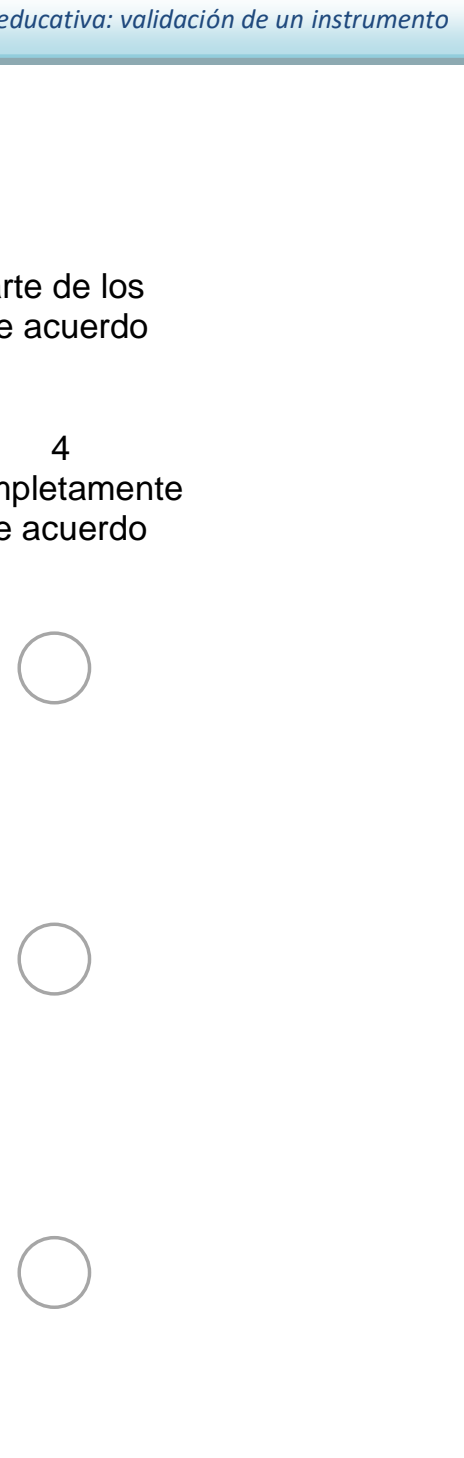

Evito utilizar el grupo para cuestiones de poca<smiles>c1ccccc1</smiles><smiles>c1ccccc1</smiles><smiles>c1ccccc1</smiles><smiles>c1ccccc1</smiles>

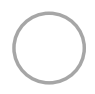

importancia

Mi participación en el centro ha mejorado gracias a su uso

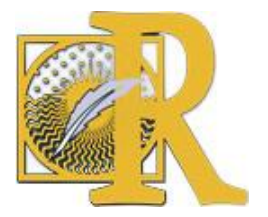

Fecha de recepción: 22-06-2019 Fecha de aceptación: 11-06-2020

Coca, P., Carpintero, E., Expósito-Casas, E., López-Martín, E. \& Thoilliez, B. (2020). Grupos de WhatsApp de padres y sus efectos en la participación educativa: validación de un instrumento International Journal of Educational Research and Innovation (IJERI), 14, 241-261 ISSN: 2386-4303 DOI https://doi.org/10.46661/ijeri.4178 
Mis hijos/as me piden que consulte algunas cuestiones a
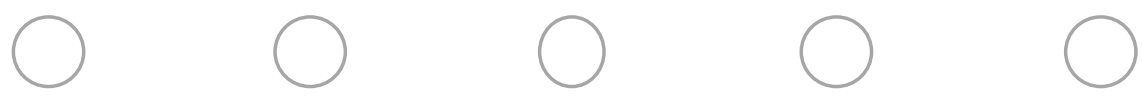

otros

padres/madres

\section{Este grupo se} ha convertido en parte de mi<smiles>c1ccccc1</smiles><smiles>c1ccccc1</smiles><smiles>c1ccccc1</smiles><smiles>c1ccccc1</smiles><smiles>c1ccccc1</smiles>
rutina diaria

He podido solucionar problemas de mis hijos/as gracias a su utilización

Me permite compartir información de interés para otras familias
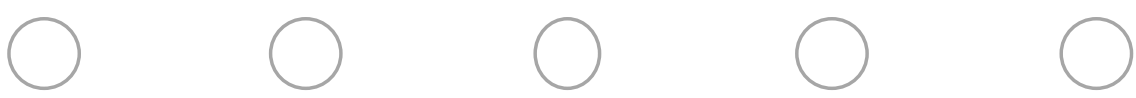

Se han generado problemas entre padres/madres
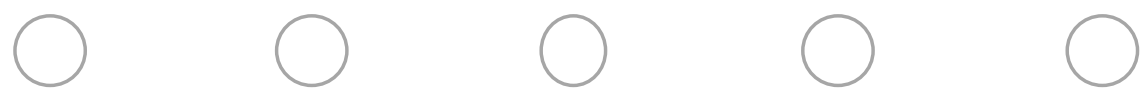

debido a algún

mal entendido

Los horarios de utilización me parecen inapropiados
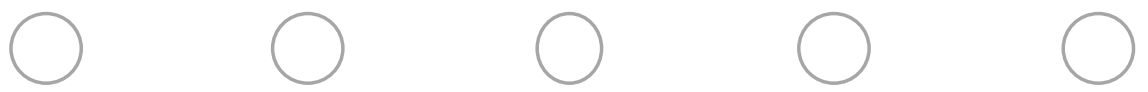

\section{¡Muchas gracias por su participación!}

